This document is the accepted manuscript version of the following article:

Urge1, J. I.; Hayashi, H.; Di Giovannantonio, M.; Pignedoli, C. A.; Mishra, S.; Deniz, O.; Yamashita, M.; Diene1, T.; Ruffieux, P.; Yamada, H.; et a1. On-surface synthesis of heptacene organometallic complexes. Journal of the American Chemical Society 2017, 139 (34), 11658-11661. http://dx.doi.org/10.1021/jacs.7b05192

\title{
On-surface synthesis of heptacene organometallic complexes
}

\author{
José I. Urgel, ${ }^{\dagger}$ Hironobu Hayashi, ${ }^{\ddagger}$ Marco Di Giovannantonio, ${ }^{\dagger}$ Carlo A. Pignedoli, ${ }^{\dagger},+$ Shantanu Mishra, ${ }^{\dagger}$ \\ Okan Deniz, ${ }^{\dagger}$ Masataka Yamashita, ${ }^{\ddagger}$ Thomas Dienel, ${ }^{\dagger}$ Pascal Ruffieux, ${ }^{\dagger}$ Hiroko Yamada, ${ }^{*},{ }^{\ddagger}$ and Roman \\ Fasel $^{* \dagger, \S}$ \\ $\dagger$ Empa, Swiss Federal Laboratories for Material Science and Technology, 8600 Dübendorf, Switzerland. \\ + NCCR MARVEL Empa, Swiss Federal Laboratories for Material Science and Technology, 8600 Dübendorf, Switzerland. \\ ¥ Graduate School of Materials Science, Nara Institute of Science and Technology (NAIST), 8916-5 Takayama-cho, Ikoma \\ 630-0192, Japan.
}

$\S$ Department of Chemistry and Biochemistry, University of Bern, Freiestrasse 3, 3012 Bern, Switzerland.

\begin{abstract}
We report the on-surface formation of Au-directed heptacene organometallic complexes on a $\mathrm{Au}(111)$ template in an ultrahigh vacuum environment. Successive thermal annealing steps investigated by means of scanning tunneling microscopy, non-contact atomic force microscopy, temperature-programmed desorption and density functional theory reveal the formation of heptacene organometallic complexes via a selective two-step activation of an $\alpha$-diketone-protected heptacene precursor. Furthermore we demonstrate the efficiency of tip-induced deprotection experiments as a complementary strategy in the complex formation. Our results provide perspectives for the on-surface synthesis of larger acenes featuring potential use in the fields of organic electronics, spintronics and nonlinear optics.
\end{abstract}

Acenes are a family of polycyclic aromatic hydrocarbons (PAHs) formed by linearly fused benzene rings. This class of compounds has received exceptional attention due to their great potential as functional organic semiconductors because of their noteworthy small HOMO-LUMO gap in comparison with other PAHs with comparable number of aromatic rings. ${ }^{1-3}$ Furthermore, acenes have been the subject of intensive theoretical investigations in recent years. ${ }^{4}$ Their electronic properties have been of fundamental theoretical interest, with various early studies predicting conflicting results on the nature of their ground state. Studies employing more sophisticated levels of theory predict short acenes (number of benzene rings $m<5$ or 6 ) to possess a closed-shell singlet ground state, with higher acenes evolving remarkably towards a polyradical singlet ground state with nearest neighbor antiferromagnetic coupling. ${ }^{5-7}$ Unfortunately, the poor solubility and the notable decrease in stability with increasing acene length make their synthesis, functionalization and characterization a challenging task. Only recently significant advances towards the synthesis of larger acenes have been accomplished. ${ }^{8-}$

${ }^{10}$ For instance, photochemically induced bisdecarbonylation of bridged $\alpha$-diketone groups using matrix-isolation techniques or thermally induced cycloreversion from diheptacenes in the solid state have been found as successful strategies for the synthesis of heptacene ${ }^{11}$ to nonacene compounds. ${ }^{12,13}$

In this context, complementary surface-assisted techniques provide an appealing playground for the investigation of larger acene compounds. ${ }^{14}$ While in the last years acenes and their derivatives have been extensively investigated on metallic single crystals, ${ }^{14-17}$ insulating films, ${ }^{16,18,19}$ or by solution chemistry, ${ }^{12,13,20-24}$ this communication provides to the best of our knowledge, the first direct visualization of a large acene $(\mathrm{m}>6)$ and its gold organometallic complexes and highlights the capability to exploit onsurface synthesis protocols in the formation of larger acene species, which remain challenging in light of the significant decrease in stability as the acene length is enlarged. On-surface chemical reactions have proven to be a versatile tool for the formation of stable molecular structures that cannot be synthesized in solution. Over the last decades, several types of on-surface reactions such as metal-organic coordination, ${ }^{25-27}$ aryl-aryl coupling ${ }^{28-30}$, cyclodehydrogenation $^{31}$ or covalent organometallic bond formation $^{32,33}$ have been extensively investigated by means of scanning probe microscopies (SPM) and other surface analysis techniques. Particularly interesting are gold-organometallic complexes due to the frequent use of gold as metal electrode in the construction of single-molecule circuits, ${ }^{34-36}$ organic electronic devices ${ }^{37}$ and next-generation carbon-based electronics. ${ }^{30,38}$

Here, we introduce an exemplary approach towards the surfaceconfined formation of large acene organometallic complexes. To this end, we synthetized an $\alpha$-diketone-type heptacene precursor (1) that can be sublimed intact and converted to heptacene by thermal activation on the metal surface under ultra-high vacuum (UHV) conditions. To ensure the controlled reaction to form goldorganometallic complexes in one direction, heptacene precursors were bromine substituted at 7,16-positions (for synthetic details and characterization see Scheme S1 and Figures S1-S3 in the Supplementary Information). Specifically, (1) consists of a nonplanar dibromo-substituted heptacene core functionalized with two $\alpha$-diketone groups which guarantee the thermal stability upon sublimation onto a coinage metal surface. Note that, the syn and anti conformers, caused by the introduction of the two $\alpha$-diketone groups, were successfully separated during the purification. Scheme 1 illustrates the two anticipated on-surface complexation reactions of (1) in the formation of Au-directed heptacene organometallic nanostructures on a bare $\mathrm{Au}(111)$ substrate. In a first annealing step, the debromination of (1) is induced and the formation of Au-directed heptacene precursor organometallic complexes (2) is achieved. A second annealing step activates the 


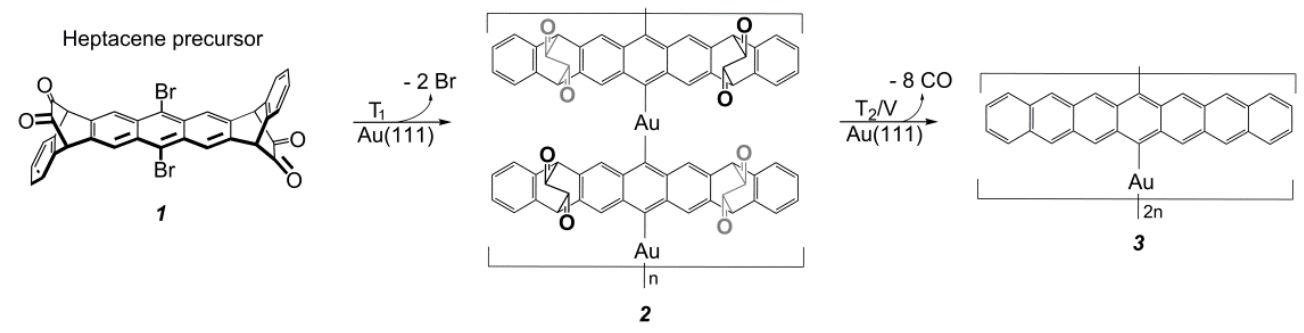

Scheme 1. On-surface synthesis of Au-directed heptacene organometallic complexes.

In order to investigate the on-surface reactions depicted in Scheme 1, a submonolayer coverage of the heptacene precursor (1) was sublimated onto the $\mathrm{Au}(111)$ substrate held at room temperature and subsequently annealed to $435 \mathrm{~K}$ to induce dehalogenation. Figures 1 a,b show constant-current scanning tunneling microscopy (STM) images of the resulting molecular layer (2) that coexists with some disordered regions. These densely-packed arrays of (2) are stabilized by lateral gold-carbon interactions, after the halogen detachment from (1). The observed intermolecular spacing of $7.4 \pm 0.3 \AA$ implies a length for the $\mathrm{C}$-Au bond of $2.3 \pm 0.2 \AA$, in agreement with previous $\mathrm{C}$-Au bond lengths reported in the literature. ${ }^{39,40}$ Organometallic intermediates have been predicted by theory and demonstrated by recent STM studies both on $\mathrm{Cu}(111)$ and $\mathrm{Ag}(111)$ substrates, ${ }^{41-47}$ but stable organometallic complexes on a $\mathrm{Au}(111)$ substrate were rarely reported. ${ }^{33,39}$ A closer look allows us to discern the intramolecular features of (2) where two protrusions of different apparent heights (4.2 $\AA$ and $3.3 \AA$, respectively) are distinguished (Figure 1c). We attribute the different appearance of the molecular features to the anti conformation, where the out-of-plane benzene ring corresponds to the higher apparent height and the $\alpha$-diketone group to the lower one (see Figure S4 for simulated STM images of a synmolecule adsorbed on $\mathrm{Au}(111)$ ). Topographic STM images of (2) are complemented by a simulated STM image based on density functional theory (DFT) calculations ( $c f$. Figures 1d,e) which fully reproduces the main features of the experimental data (see Supporting information for details).
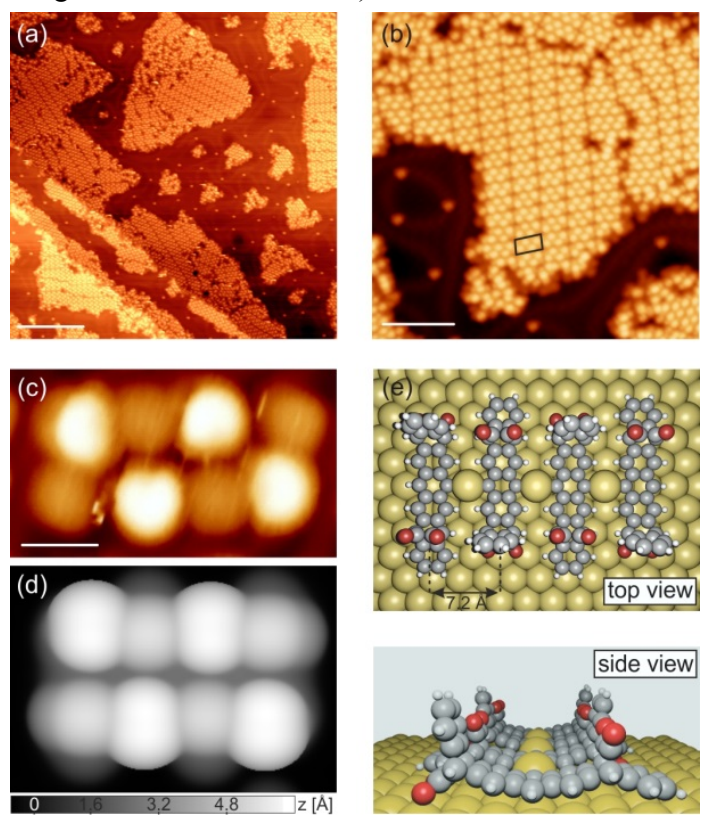

Figure 1. Organometallic complex formation via debromination of heptacene precursor (1) on $\mathrm{Au}(111)$. (a) Large-scale STM image of the organometallic complexes after a first annealing step at 460 $\mathrm{K}$ to induce debromination. $\mathrm{V}_{\mathrm{b}}=-1.5 \mathrm{~V}, \mathrm{I}=20 \mathrm{pA}$. Scale bar: 20 $\mathrm{nm}$. (b) Magnified view of the organometallic nanostructure in (a) evidencing the presence of intramolecular features with two different apparent heights. A black rectangle highlights four heptacene precursors linked by three gold atoms as described in (c-e). $\mathrm{V}_{\mathrm{b}}=-2.2 \mathrm{~V}, \mathrm{I}=40 \mathrm{pA}$. Scale bar: $8 \mathrm{~nm}$. (c) High-resolution STM image of a Au-directed tetramer of heptacene precursors adsorbed on $\mathrm{Au}(111) . \mathrm{V}_{\mathrm{b}}=-2.2 \mathrm{~V}, \mathrm{I}=40 \mathrm{pA}$. Scale bar: $1 \mathrm{~nm}$. (d) DFT simulated STM image of (c). $V_{b}=-2.0 \mathrm{eV}$. (e) Top and side views of the corresponding DFT equilibrium geometry.

After a second annealing step to $535 \mathrm{~K}$ the cleavage of $\alpha$ diketone moieties from (2) is achieved as shown in Figure 2. New species appearing as chains with lower apparent height $(1.6 \AA)$ are visible, which are assigned to heptacene organometallic complexes (3). Figures $2 b, c$ show a more detailed examination of a heptacene-Au-heptacene organometallic complex. A seven-lobed species linked by single bright protrusions and a C-Au bond length of $2.5 \pm 0.2 \AA$ can be determined. DFT simulations of the heptaceneAu-heptacene complex are depicted in Figure 2c (STM image) and $2 \mathrm{~d}$ (equilibrium geometry). The agreement between simulated and experimental STM and the evidence of seven distinct "lobes" along the monomers reveals that the HOMO of heptacene is mainly contributing to the signal. In the DFT equilibrium geometry, the $\mathrm{Au}$ adatom is located $3.06 \AA$ above the first substrate layer with a $\mathrm{C}-\mathrm{Au}$ bond length of $2.1 \AA$, in good agreement with our experimental values. Moreover, heptacene molecules are slightly tilted $\left(5.6^{\circ}\right)$ towards the $\mathrm{Au}$ adatom and bended $\left(6^{\circ}\right)$ along their main axis inducing a slightly higher adsorption height for the heptacene termini. Importantly, the formation of the heptacene molecular entities is attributed to the cleaving of the protecting moieties, i.e., the $\alpha$-diketone groups, during the annealing step. Using temperature-programmed desorption experiments (TPD), we determine the desorption of molecular protecting groups as $\mathrm{CO}$ molecules with maximum desorption rate at about $510 \mathrm{~K}$ (cf. Figure 2e). This result clearly indicates that photoreactive $\alpha$ diketone moieties ${ }^{12,13,23}$ can also act as thermally active groups on a metal surface. To confirm the chemical structure of the resulting organometallic chains, non-contact atomic force microscopy (nc$\mathrm{AFM}$ ) measurements using a $\mathrm{CO}$-functionalized tip were performed. ${ }^{48}$ Figure $2 \mathrm{f}$ depicts the resulting constant-height frequency-shift image where features assigned to the seven benzene rings of each heptacene molecule linked by a central bright lobe of an increased frequency shift are resolved. It should be noted that the length of the complex can vary ranging from 2 to 9 heptacene units, whereby $76 \%$ of the complexes present from 2 to 4 units (statistics out of $\sim 900$ molecules, Supporting Figure S5). This 
fact is tentatively associated to the presence of hydrogen residual gas in the vacuum chamber which inhibits the formation of longer organometallic chains by hydrogen passivation of the radical sites, which even leads to the sporadic formation of individual heptacene species. ( $c f$. rod-like molecular entities in Figure $2 \mathrm{a}$ and Supporting Figure S6). We note that due to the steric hindrance between the hydrogens further annealing does not give rise to aryl-aryl coupling between heptacene species.

At this point, a comment regarding the advantages and disadvantages of the presented on-surface synthesis and characterization approach is appropriate. While this approach allows for a detailed characterization at the single-molecule level by means of scanning probe methods, ${ }^{49}$ transfer of the products to another substrate or an organic solvent for further characterization by more traditional methods such as mass spectrometry or optical methods is generally not straightforward. Also, such characterization would be extremely challenging due to the tiny (submonolayer) amount of products. Nevertheless, the possibility to directly visualize the products with submolecular resolution makes this approach a highly attractive alternative to matrix isolation, ${ }^{12,13}$ thin film ${ }^{11}$ and more traditional solution environment studies. ${ }^{23,50-}$ 53
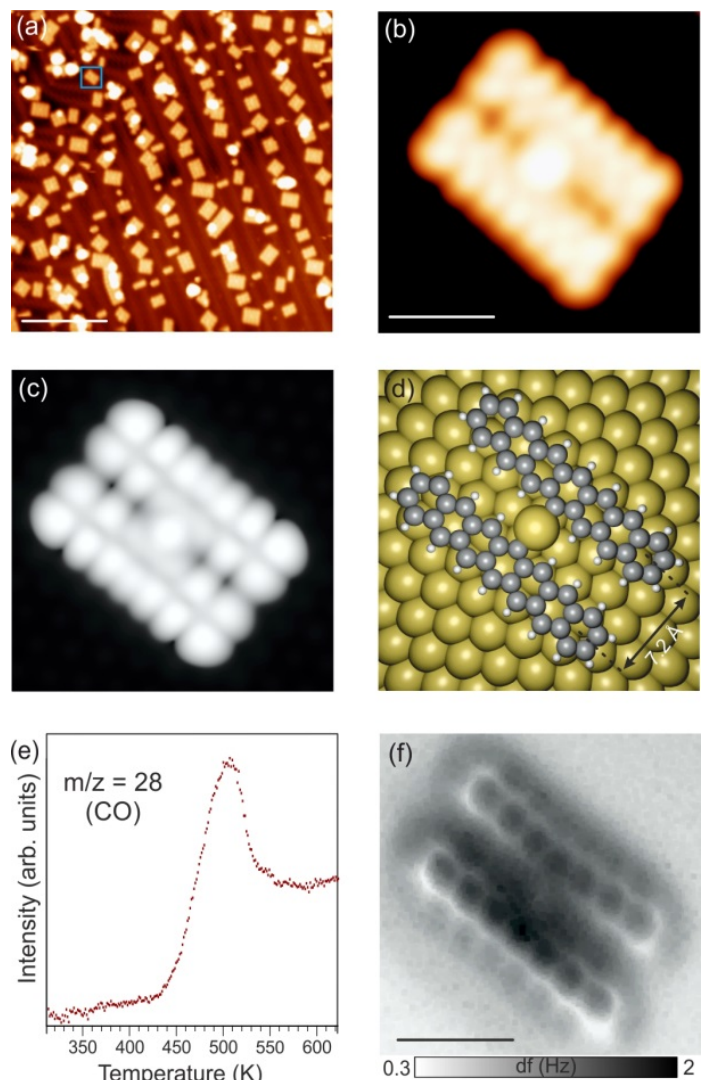

Figure 2. Thermal conversion of heptacene precursors on the $\mathrm{Au}(111)$ substrate. (a) Large-scale STM image of the heptacene organometallic complexes after a second annealing step at $535 \mathrm{~K}$. $\mathrm{V}_{\mathrm{b}}=-2.5 \mathrm{~V}, \mathrm{I}=7 \mathrm{pA}$. Scale bar: $15 \mathrm{~nm}$. (b) High-resolution STM image of a heptacene-Au-heptacene organometallic complex (or $\mathrm{Au}$-directed heptacene dimer) where intramolecular features are distinguished. $\mathrm{V}_{\mathrm{b}}=-1.5 \mathrm{~V}, \mathrm{I}=70 \mathrm{pA}$. Scale bar: $1 \mathrm{~nm}$. (c) DFT simulated STM image of (b) at $-1.5 \mathrm{eV}$. (d) Top view of the DFT equilibrium geometry of a heptacene-Au-heptacene organometallic complex adsorbed on a $\mathrm{Au}(111)$ slab. (e) TPD graph showing the desorption of $\alpha$-diketone groups as $\mathrm{CO}$ molecules with a maximum desorption rate at $510 \mathrm{~K}$ (heating rate $2 \mathrm{~K} / \mathrm{s}$ ). (f) Constant-height frequency-shift nc-AFM image of (b) acquired with a
CO-functionalized tip ( $\mathrm{z}$ offset $-30 \mathrm{pm}$ below STM set point: 5 $\mathrm{mV}, 10 \mathrm{pA})$. Scale bar $=1 \mathrm{~nm}$.

Finally, we have further extended our on-surface synthesis approach by investigating the tip-induced cleaving of $\alpha$-diketone groups in (2). Figure 3 summarizes a typical tip-induced deprotection experiment. Here, the STM tip is positioned at a fixed location above an $\alpha$-diketone functional group in the heptacene derivative organometallic complexes (2) (Figure 3a). Next, a voltage ramp $(-1.0$ to $-3.0 \mathrm{~V})$ is applied to the sample with feedback loop off. We observe a sudden decrease in the current signal with a threshold at $-2.8 \pm 0.2 \mathrm{~V}$, which is assigned to the cleaving of $\alpha$ diketone moieties, i.e, formation of heptacene organometallic complexes (3), as is confirmed by a subsequent STM scan of the same area (Figure 3b, full sequence in Supporting Figure S7). Moreover, similar tip-induced deprotection experiments starting from room temperature deposition of the heptacene precursor (1) to obtain individual dibromo-heptacene species have been realized (Figure S8). Such experiments are in agreement with previously reported work where STM tip-induced activation of selective functional side groups was observed. . $^{17,54,55}$

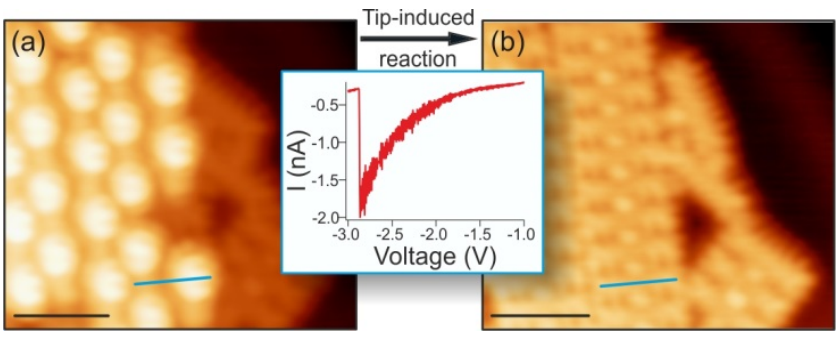

Figure 3. Tip-induced deprotection of Au-directed heptacene derivative organometallic complexes on $\mathrm{Au}(111)$. (a) Highresolution STM image of Au-directed heptacene derivative organometallic complexes. (b) High-resolution STM image of Audirected heptacene organometallic complexes after the tip-induced conversion. $\mathrm{V}_{\mathrm{b}}=-1.7 \mathrm{~V}, \mathrm{I}=5 \mathrm{pA}$. Scale bar: $2 \mathrm{~nm}$. Blue lines are depicted as a guide to the eye for a single molecule in $(a-b)$. The overlaid I-V curve shows a typical threshold voltage for the tipinduced reaction.

In conclusion, we have introduced protocols for the on-surface synthesis of Au-directed heptacene organometallic complexes on a coinage metal template. Following a two-step procedure, large acene complexes can be achieved. Upon a first annealing step to $435 \mathrm{~K}$ the formation of heptacene derivative organometallic complexes was promoted. A subsequent annealing step at $535 \mathrm{~K}$ leads to the cleaving of the $\alpha$-diketone groups producing the corresponding heptacene organometallic complexes. Additionally, tipinduced deprotection experiments were performed allowing us to deliberately detach the $\alpha$-diketone groups with exquisite spatial control. We expect that our approach is of general relevance for the synthesis and characterization of larger acenes and their derivatives, thus opening new avenues in the field of on-surface synthesis with prospects for applications in opto- and molecular electronics.

\section{Supporting Information}

Synthesis of the molecular precursor (1). Experimental and theoretical procedures including additional STM, nc-AFM, DFT data and histogram showing the length of heptacene organometallic complexes. This material is available free of charge via the Internet at http://pubs. acs.org.

\section{AUTHOR INFORMATION}




\section{Corresponding Author}

*E-mail: roman.fasel@empa.ch

*E-mail: hyamada@ms.naist.jp

Notes

The authors declare no competing financial interest.

\section{Author Contributions}

The manuscript was written through contributions of all authors. All authors have given approval to the final version of the manuscript. José I. Urgel and Hironobu Hayashi contributed equally.

\section{ACKNOWLEDGMENTS}

This work was supported by the Swiss National Science Foundation; the Graphene Flagship (No. CNECT-ICT-604391); the Office of Naval Research BRC program; CREST JST (JPMJCR15F1); JSPS KAKENHI (JP15K17843 and JP16H02286); and MEXT KAKENHI (JP26105004). We thank Ms. Y. Nishikawa for the mass spectroscopy measurements. The Swiss National Supercomputing Center (CSCS) is acknowledged for computational resources.

\section{REFERENCES}

(1) Anthony, J. E. Angew. Chem. Int. Ed. 2008, 47, 452.

(2) Sun, Z.; Ye, Q.; Chi, C.; Wu, J. Chem. Soc. Rev. 2012, 41, 7857.

(3) Ye, Q.; Chi, C. Chem. Mater. 2014, 26, 4046.

(4) Bettinger, H. F. Pure Appl. Chem. 2010, 82, 905.

(5) Hachmann, J.; Dorando, J. J.; Avilés, M.; Chan, G. K.-L. J. Chem. Phys. 2007, 127, 134309.

(6) Jiang, D.; Dai, S. J. Phys. Chem. A 2008, 112, 332.

(7) Plasser, F.; Pašalić, H.; Gerzabek, M. H.; Libisch, F.; Reiter, R.; Burgdörfer, J.; Müller, T.; Shepard, R.; Lischka, H. Angew. Chem. Int. Ed. 2013, 52, 2581.

(8) Dorel, R.; Echavarren, A. M. Eur. J. Org. Chem. 2017, 2017, 1.

(9) Bettinger, H. F.; Tönshoff, C. Chem. Rec. 2015, 15, 364.

(10) Zade, S. S.; Bendikov, M. Angew. Chem. Int. Ed. 2010, 49, 4012.

(11) Einholz, R.; Fang, T.; Berger, R.; Grüninger, P.; Früh, A.; Chassé, T.; Fink, R. F.; Bettinger, H. F. J. Am. Chem. Soc. 2017, 139, 4435.

(12) Mondal, R.; Shah, B. K.; Neckers, D. C. J. Am. Chem. Soc. 2006, 128, 9612.

(13) Tönshoff, C.; Bettinger, H. F. Angew. Chem. Int. Ed. 2010, 49, 4125.

(14) Krüger, J.; Eisenhut, F.; Alonso, J. M.; Lehmann, T.; Guitián, E.; Pérez, D.; Skidin, D.; Gamaleja, F.; Ryndyk, D. A.; Joachim, C.; Peña, D.; Moresco, F.; Cuniberti, G. Chem. Commun. 2017, 53, 1583.

(15) Soe, W.-H.; Manzano, C.; De Sarkar, A.; Chandrasekhar, N.; Joachim, C. Phys. Rev. Lett. 2009, 102, 176102.

(16) Gross, L.; Mohn, F.; Moll, N.; Liljeroth, P.; Meyer, G. Science 2009, 325, 1110.

(17) Krüger, J.; Pavliček, N.; Alonso, J. M.; Pérez, D.; Guitián, E.; Lehmann, T.; Cuniberti, G.; Gourdon, A.; Meyer, G.; Gross, L.; Moresco, F.; Peña, D. ACS Nano 2016, 10, 4538.

(18) Repp, J.; Meyer, G.; Stojković, S. M.; Gourdon, A.; Joachim, C. Phys. Rev. Lett. 2005, 94, 026803.

(19) Repp, J.; Meyer, G.; Paavilainen, S.; Olsson, F. E.; Persson, M. Science 2006, 312, 1196.
(20) Watanabe, M.; Chang, Y. J.; Liu, S.-W.; Chao, T.-H.; Goto, K.; Islam, M. M.; Yuan, C.-H.; Tao, Y.-T.; Shinmyozu, T.; Chow, T. J. Nat. Chem. 2012, 4, 574.

(21) Kaur, I.; Jazdzyk, M.; Stein, N. N.; Prusevich, P.; Miller, G. P. J. Am. Chem. Soc. 2010, 132, 1261.

(22) Anthony, J. E.; Brooks, J. S.; Eaton, D. L.; Parkin, S. R. J. Am. Chem. Soc. 2001, 38, 9482.

(23) Yamada, H.; Yamashita, Y.; Kikuchi, M.; Watanabe, H.; Okujima, T.; Uno, H.; Ogawa, T.; Ohara, K.; Ono, N. Chem. - Eur. J. 2005, 11, 6212.

(24) Tanaka, K.; Aratani, N.; Kuzuhara, D.; Sakamoto, S.; Okujima, T.; Ono, N.; Uno, H.; Yamada, H. RSC Adv. 2013, 3, 15310.

(25) Annu. Rev. Phys. Chem. 2007, 58, 375.

(26) AIP Conf. Proc. 2003, 696, 144.

(27) Dong, L.; Gao, Z.; Lin, N. Prog. Surf. Sci. 2016, 91, 101.

(28) Grill, L.; Dyer, M.; Lafferentz, L.; Persson, M.; Peters, M. V.; Hecht, S. Nat. Nanotechnol. 2007, 2, 687.

(29) Fan, Q.; Wang, C.; Han, Y.; Zhu, J.; Hieringer, W.; Kuttner, J.; Hilt, G.; Gottfried, J. M. Angew. Chem. Int. Ed. 2013, 52, 4668.

(30) Cai, J.; Ruffieux, P.; Jaafar, R.; Bieri, M.; Braun, T.; Blankenburg, S.; Muoth, M.; Seitsonen, A. P.; Saleh, M.; Feng, X.; Müllen, K.; Fasel, R. Nature 2010, 466, 470.

(31) Treier, M.; Pignedoli, C. A.; Laino, T.; Rieger, R.; Müllen, K.; Passerone, D.; Fasel, R. Nat. Chem. 2011, 3, 61.

(32) Haq, S.; Hanke, F.; Dyer, M. S.; Persson, M.; Iavicoli, P.; Amabilino, D. B.; Raval, R. J. Am. Chem. Soc. 2011, 133, 12031.

(33) Zhang, H.; Chi, L. Adv. Mater. 2016, 28, 10492.

(34) Nazin, G. V.; Qiu, X. H.; Ho, W. Science 2003, 302, 77.

(35) Mohn, F.; Repp, J.; Gross, L.; Meyer, G.; Dyer, M. S.; Persson, M. Phys. Rev. Lett. 2010, 105, 266102.

(36) Quek, S. Y.; Venkataraman, L.; Choi, H. J.; Louie, S. G.; Hybertsen, M. S.; Neaton, J. B. Nano Lett. 2007, 7, 3477.

(37) Cheng, Z.-L.; Skouta, R.; Vazquez, H.; Widawsky, J. R.; Schneebeli, S.; Chen, W.; Hybertsen, M. S.; Breslow, R.; Venkataraman, L. Nat. Nanotechnol. 2011, 6, 353.

(38) Ruffieux, P.; Wang, S.; Yang, B.; Sánchez-Sánchez, C.; Liu, J.; Dienel, T.; Talirz, L.; Shinde, P.; Pignedoli, C. A.; Passerone, D.; Dumslaff, T.; Feng, X.; Müllen, K.; Fasel, R. Nature 2016, 531, 489.

(39) Zhang, H.; Franke, J.-H.; Zhong, D.; Li, Y.; Timmer, A.; Arado, O. D.; Mönig, H.; Wang, H.; Chi, L.; Wang, Z.; Müllen, K.; Fuchs, H. Small 2014, 10, 1361.

(40) Zhang, H.; Lin, H.; Sun, K.; Chen, L.; Zagranyarski, Y.; Aghdassi, N.; Duhm, S.; Li, Q.; Zhong, D.; Li, Y.; Müllen, K.; Fuchs, H.; Chi, L. J. Am. Chem. Soc. 2015, 137, 4022.

(41) Nguyen, M.-T.; Pignedoli, C. A.; Passerone, D. Phys. Chem. Chem. Phys. 2010, 13, 154.

(42) Bieri, M.; Nguyen, M.-T.; Gröning, O.; Cai, J.; Treier, M.; Aït-Mansour, K.; Ruffieux, P.; Pignedoli, C. A.; Passerone, D.; Kastler, M.; Müllen, K.; Fasel, R. J. Am. Chem. Soc. 2010, 132, 16669.

(43) Eichhorn, J.; Strunskus, T.; Rastgoo-Lahrood, A.; Samanta, D.; Schmittel, M.; Lackinger, M. Chem. Commun. 2014, 50, 7680 .

(44) Gutzler, R.; Cardenas, L.; Lipton-Duffin, J.; Garah, M. E.; Dinca, L. E.; Szakacs, C. E.; Fu, C.; Gallagher, M.; Vondráček, M.; Rybachuk, M.; Perepichka, D. F.; Rosei, F. Nanoscale 2014, 6, 2660.

(45) Di Giovannantonio, M.; El Garah, M.; Lipton-Duffin, J.; Meunier, V.; Cardenas, L.; Fagot Revurat, Y.; Cossaro, A.; Verdini, A.; Perepichka, D. F.; Rosei, F.; Contini, G. ACS Nano 2013, 7, 8190.

(46) Wang, W.; Shi, X.; Wang, S.; Van Hove, M. A.; Lin, N. J. Am. Chem. Soc. 2011, 133, 13264. 
(47) Lewis, E. A.; Murphy, C. J.; Liriano, M. L.; Sykes, E. C. H. Chem. Commun. 2013, 50, 1006.

(48) Gross, L.; Mohn, F.; Moll, N.; Liljeroth, P.; Meyer, G. Science 2009, 325, 1110.

(49) Pavliček, N.; Gross, L. Nat. Rev. Chem. 2017, 1, s41570.

(50) Purushothaman, B.; Parkin, S. R.; Anthony, J. E. Org. Lett. 2010, 12, 2060.

(51) Chun, D.; Cheng, Y.; Wudl, F. Angew. Chem. Int. Ed. 2008, 47, 8380.

(52) Kaur, I.; Stein, N. N.; Kopreski, R. P.; Miller, G. P. J. Am. Chem. Soc. 2009, 131, 3424.

(53) Purushothaman, B.; Bruzek, M.; Parkin, S. R.; Miller, A.F.; Anthony, J. E. Angew. Chem. Int. Ed. 2011, 50, 7013.

(54) Dujardin, G.; Walkup, R. E.; Avouris, P. Science 1992, 255, 1232.

(55) Martel, R.; Avouris, P.; Lyo, I.-W. Science 1996, 272, 385.

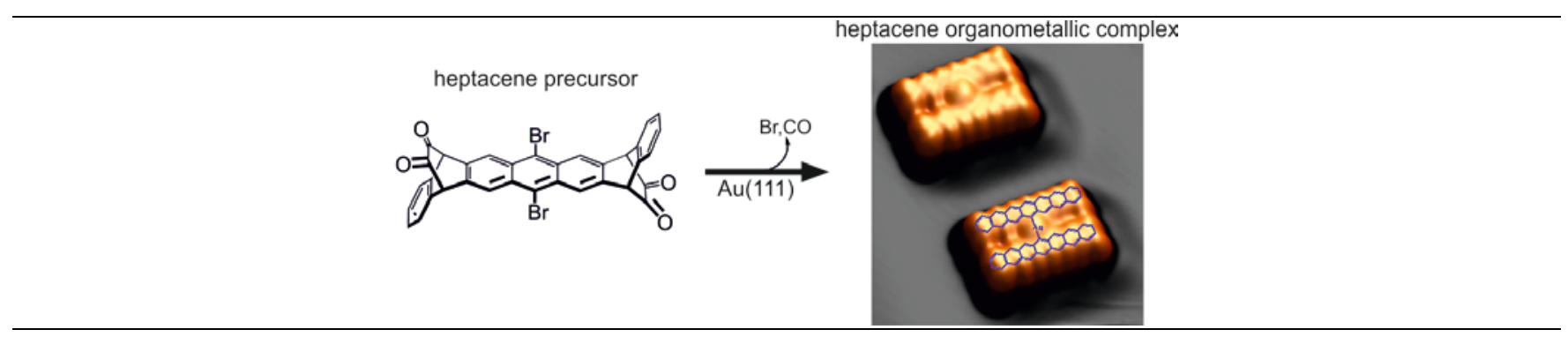

